\title{
EGU2020
}

GEOMAR

\author{
Yanan Zhao ${ }^{1}$, Cathleen Schlundt ${ }^{1}$, \\ Dennis Booge ${ }^{1}$ and Hermann Bange ${ }^{1}$
}

${ }^{1}$ GEOMAR Helmholtz Centre for

Ocean Research Kiel 


\section{Research Introduction}

- Site: Boknis Eck time-series station (SW Baltic Sea)

- Research Mission: Variability of sulphur compounds at the Boknis Eck Time-Series Station in the Baltic Sea during 2009-2018 


\section{Why we study this?}

- DMS (Dimethyl sulphide) is an important volatile organic sulfur compound and plays an important role in regulating climate change.

- Information of sulphur compounds in the Baltic Sea are very limited, DMSP and DMSO observations have even never been reported up to now compared to few DMS results. 


\section{Boknis Eck station}

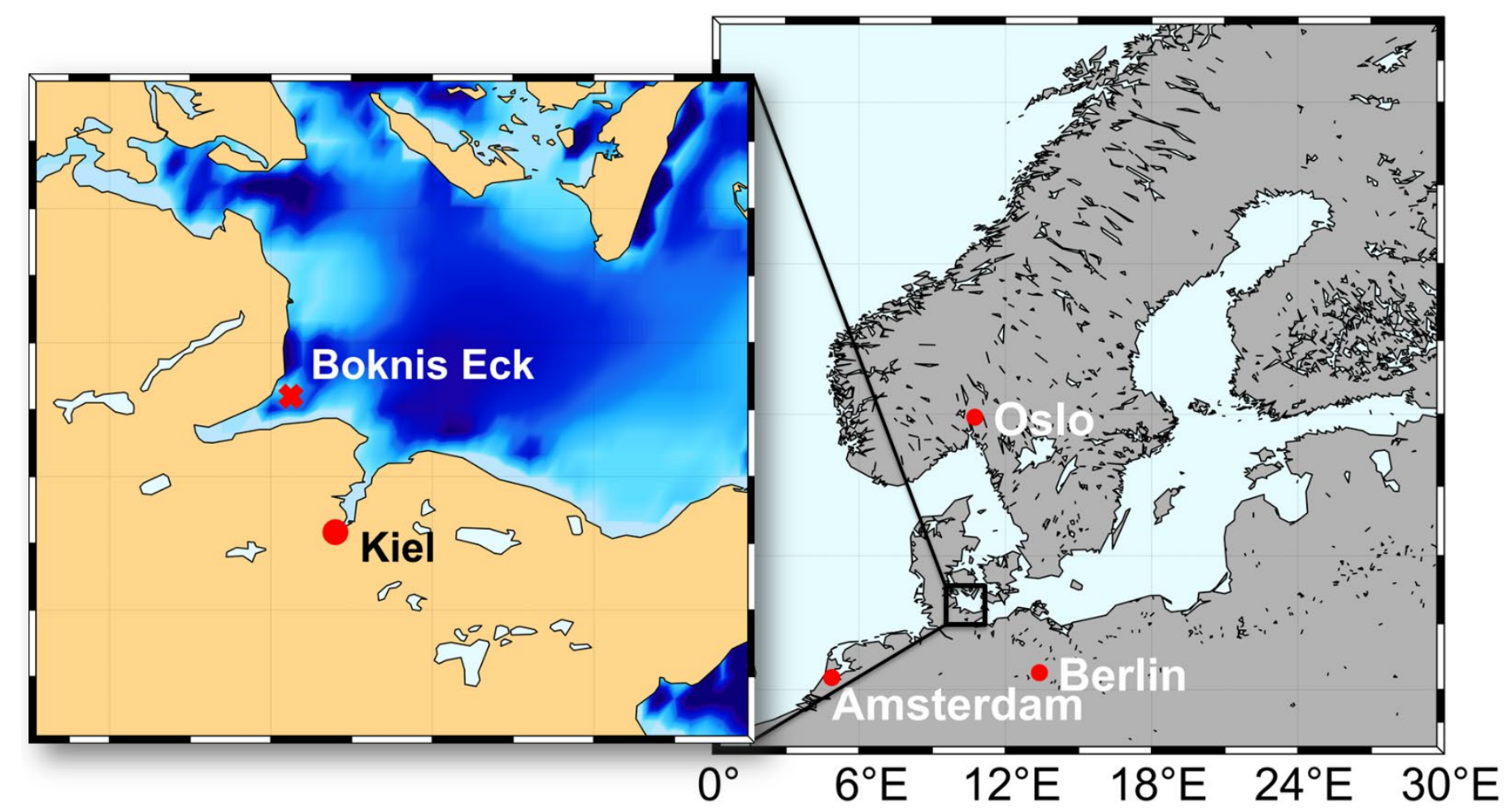

Sulphur compounds seawater samples at Boknis Eck time-series station started from 2009, with a regular monthly interval at six depths: 1, 5, 10, 15, 20 and $25 \mathrm{~m}$ (max. 28m). 


\section{Overview of the coastal setting}

Depth [m]
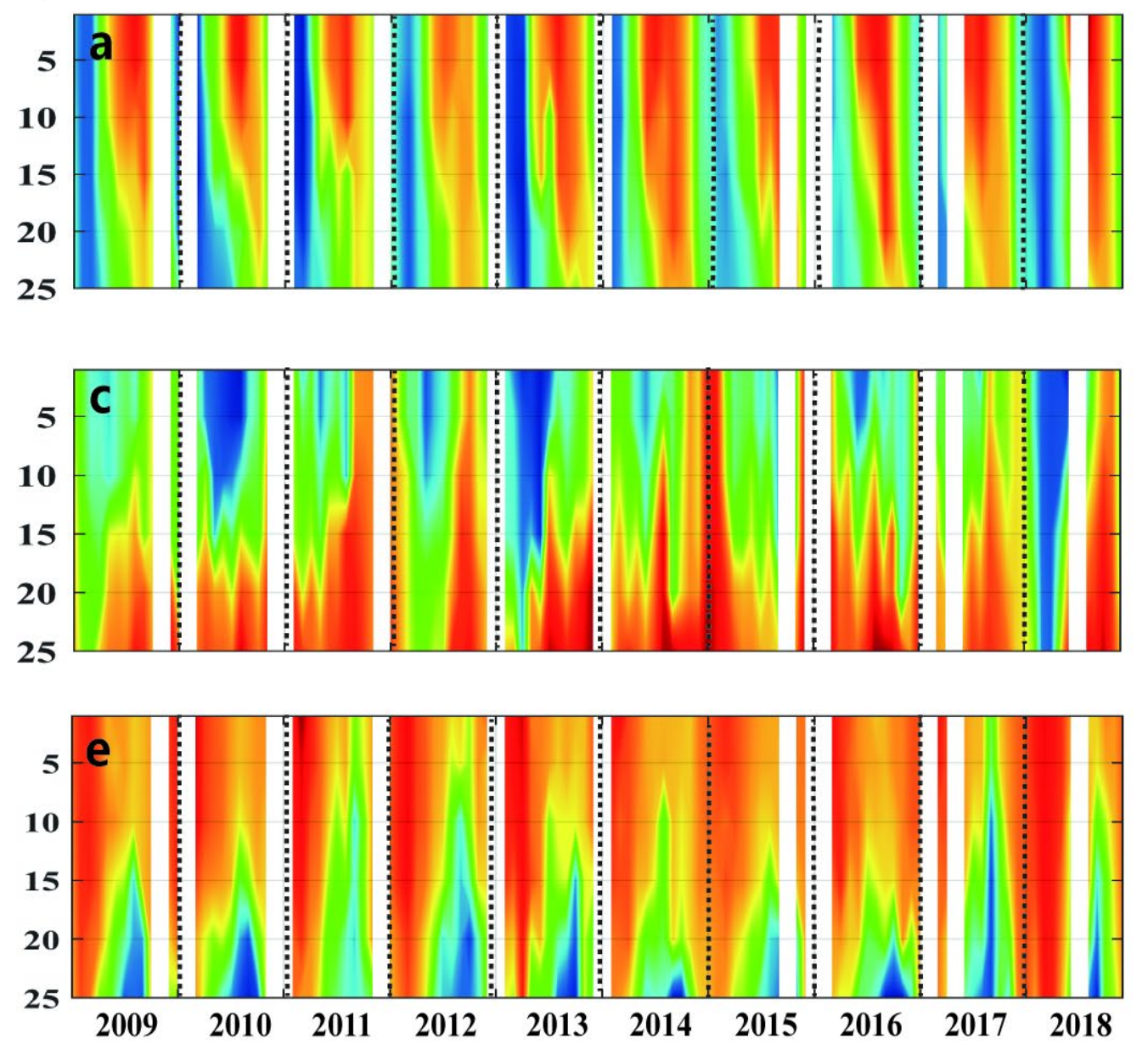

Temperature $\left[{ }^{\circ} \mathrm{C}\right]$
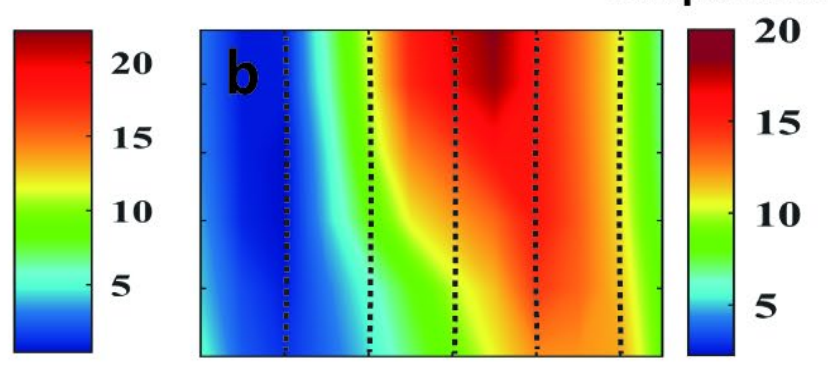

Salinity [psu]
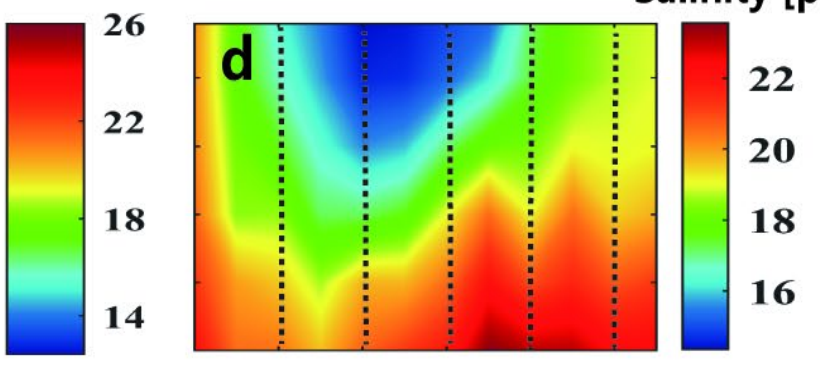

Oxygen [ $\left.\mu \mathrm{mol} \mathrm{L}^{-1}\right]$
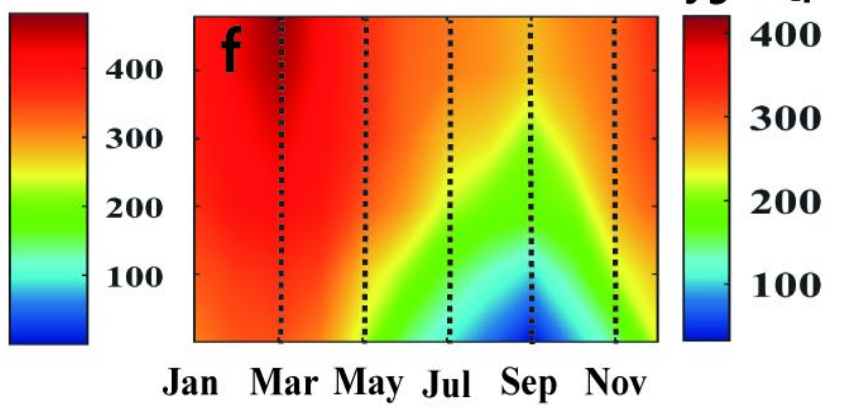

Vertical distributions and mean seasonal variations of temperature $(a, b)$, salinity (c, d) and dissolved $\mathrm{O}_{2}(\mathrm{e}, \mathrm{f})$ at the Boknis Eck station during 2009-2018. The blank area is due to the cancellation of the cruise. 


\section{Variabilities of $\mathrm{Chl}$ a and sulphur compounds}
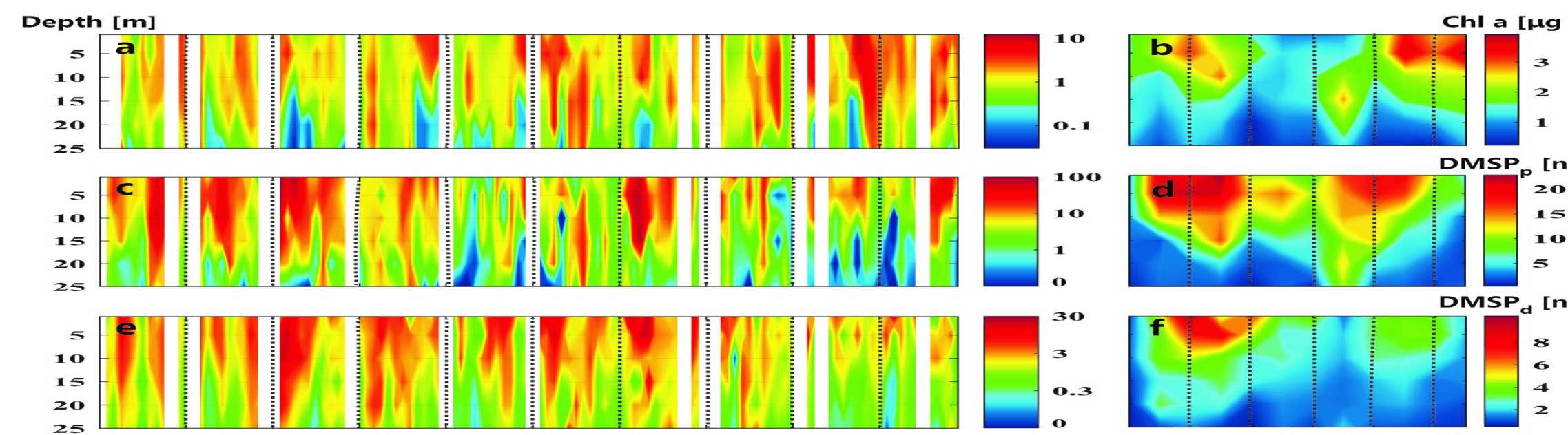

DMSP [nmolL-1]
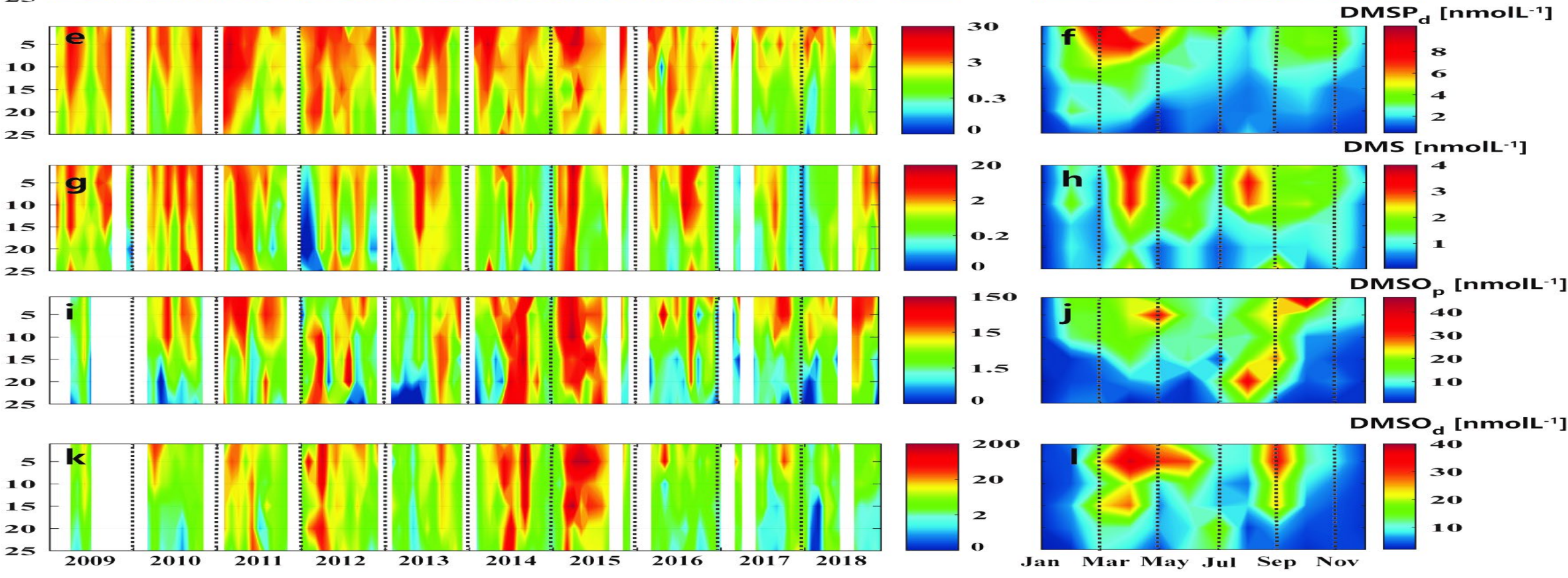

Generally, sulphur compounds followed the similar pattern with $\mathrm{Chl}$ a, with hot spots in Spring and Autumn, corresponding with phytoplankton bloom period and decreased as depths increased. Relatively high concentrations were observed between two blooms for DMS and $\mathrm{DMSP}_{\mathrm{p}}$, might be related to increasing grazing pressure of zooplankton and microbial metabolism. 


\section{Relationship between DMSP(O) and Temperature at the mixed layer depth}
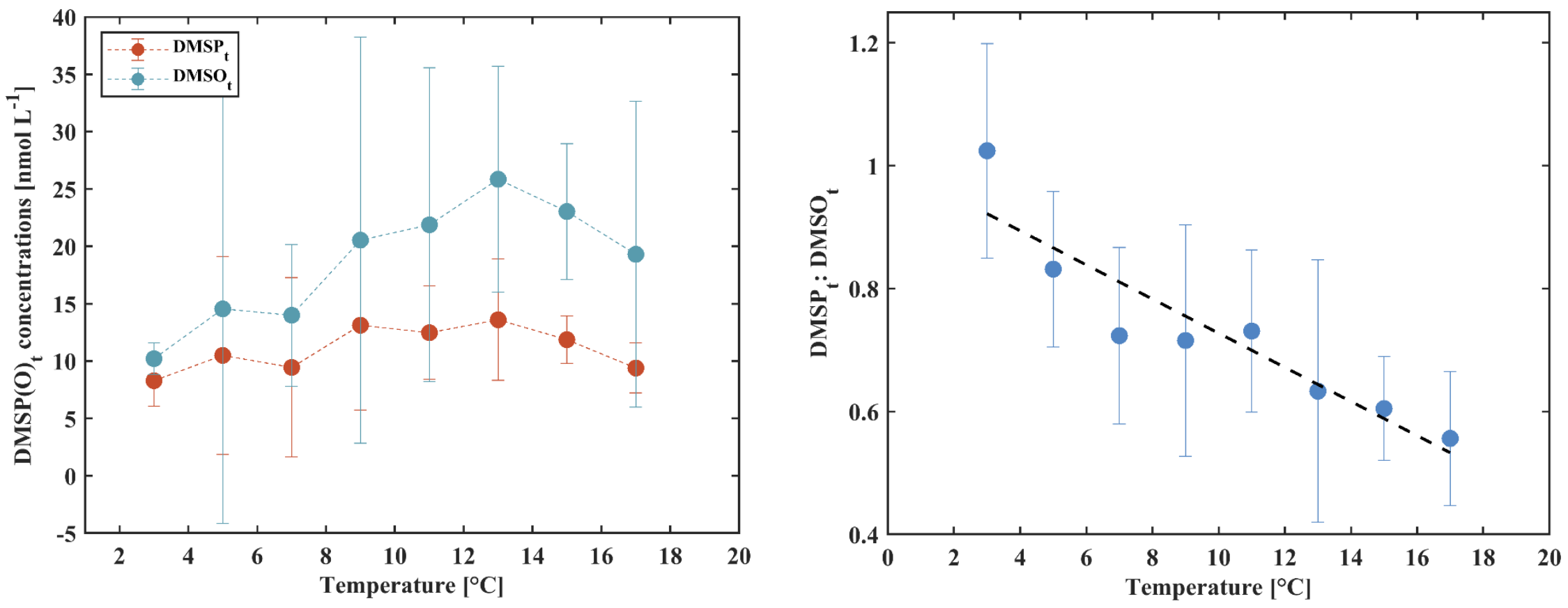

- A significant relationship between Temp and $\mathrm{DMSP}_{\mathrm{t}}: \mathrm{DMSO}_{\mathrm{t}}$ ratio.

- Linear regression in the right: $y=-0.03 x+1.01, R^{2}=0.85, p<0.01$.

- The negative relationship might be in relation to the improvement of DMS metabolism which enhanced DMSPDMS-DMSO production chain, and a enhanced cascade reaction system which induced by high solar radiation (represented by Temp), triggering increased DMSO (as a radical scavenger) production, can't be ignored. 


\section{Relationship between DMSP(O) and Salinity at the mixed layer depth}
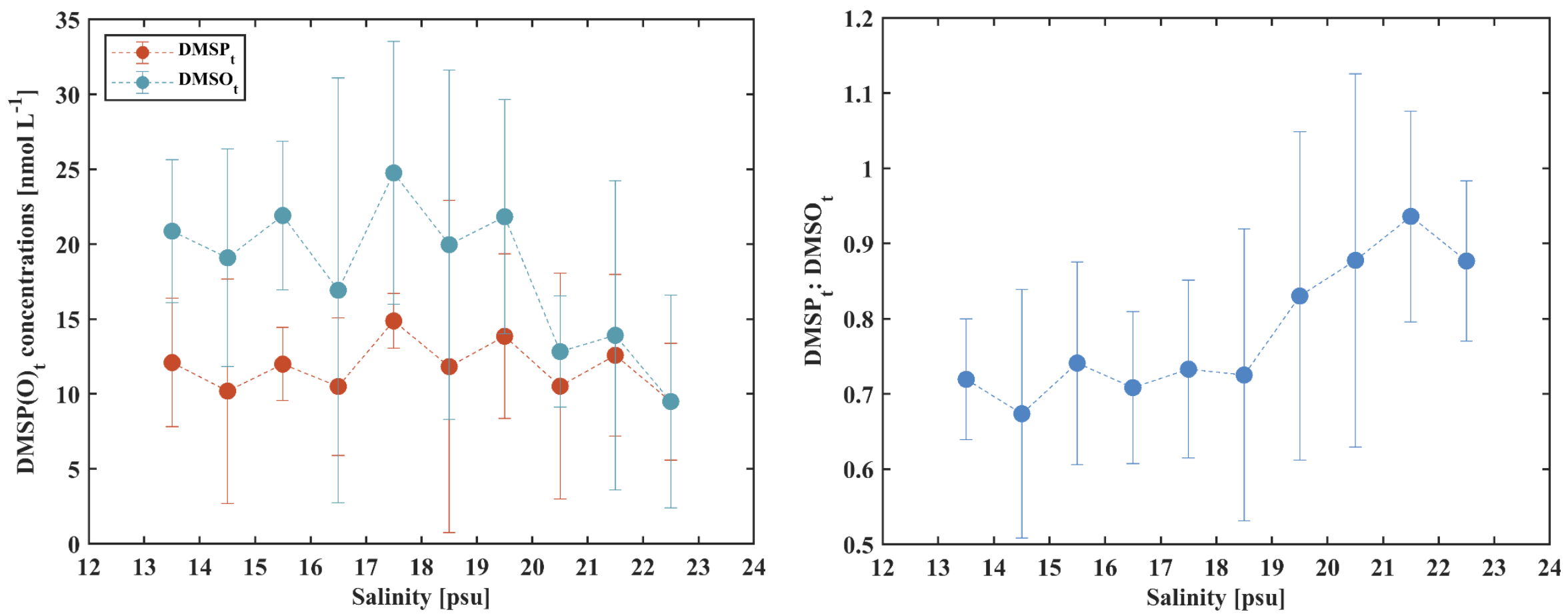

- The relationship between Salinity and $\mathrm{DMSP}_{\mathrm{t}}: \mathrm{DMSO}_{\mathrm{t}}$ ratio.

- DMSP $_{t}$ and $\mathrm{DMSO}_{\mathrm{t}}$ concentrations kept stable before salinity reaching around $20 \mathrm{psu}, \mathrm{a}$ dropping occurred as salinity increased after 20 psu might be related with upwelling events which brought cooler seawater and(or) hypoxic seawater from bottom to the surface, therefore, affecting the production of $\mathrm{DMSO}_{\mathrm{t}}$. 


\section{Relationship between DMSP(O) and N:P at the mixed layer depth}
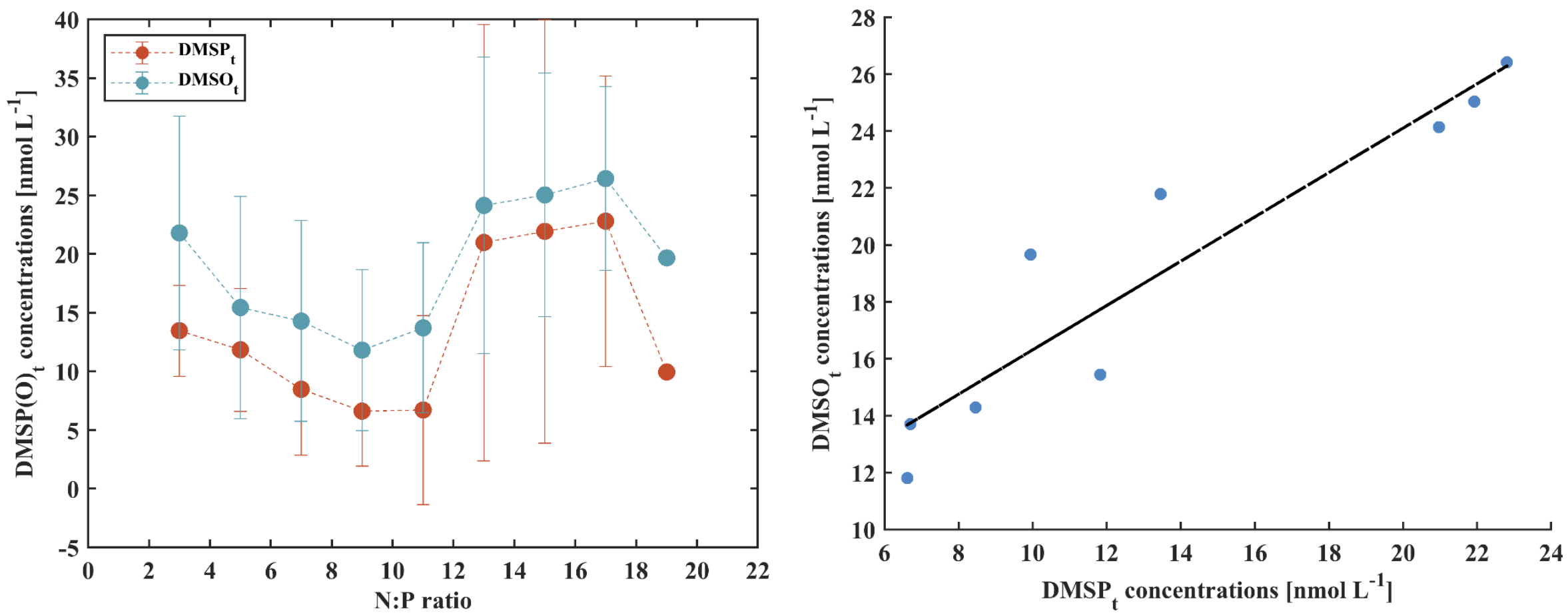

- The relationship between $\mathrm{N}: \mathrm{P}$ ratio and $\mathrm{DMSP}_{\mathrm{t}}$ : $\mathrm{DMSO}_{\mathrm{t}}$ ratio.

- Linear regression in the right: $\mathrm{y}=0.78 \mathrm{x}+8.52, R^{2}=0.88, p<0.01$.

- $\mathrm{DMSP}_{\mathrm{t}}$ and $\mathrm{DMSO}_{\mathrm{t}}$ followed the same pattern responding to the nitrogen stress, indicating that they might be produced from same origin and their production were limited under $\mathrm{N}$ limitation. 


\section{Relationship between DMSP $(0)_{p}$ and $\mathrm{Chl}$ a concentrations at the Mixed layer depth}

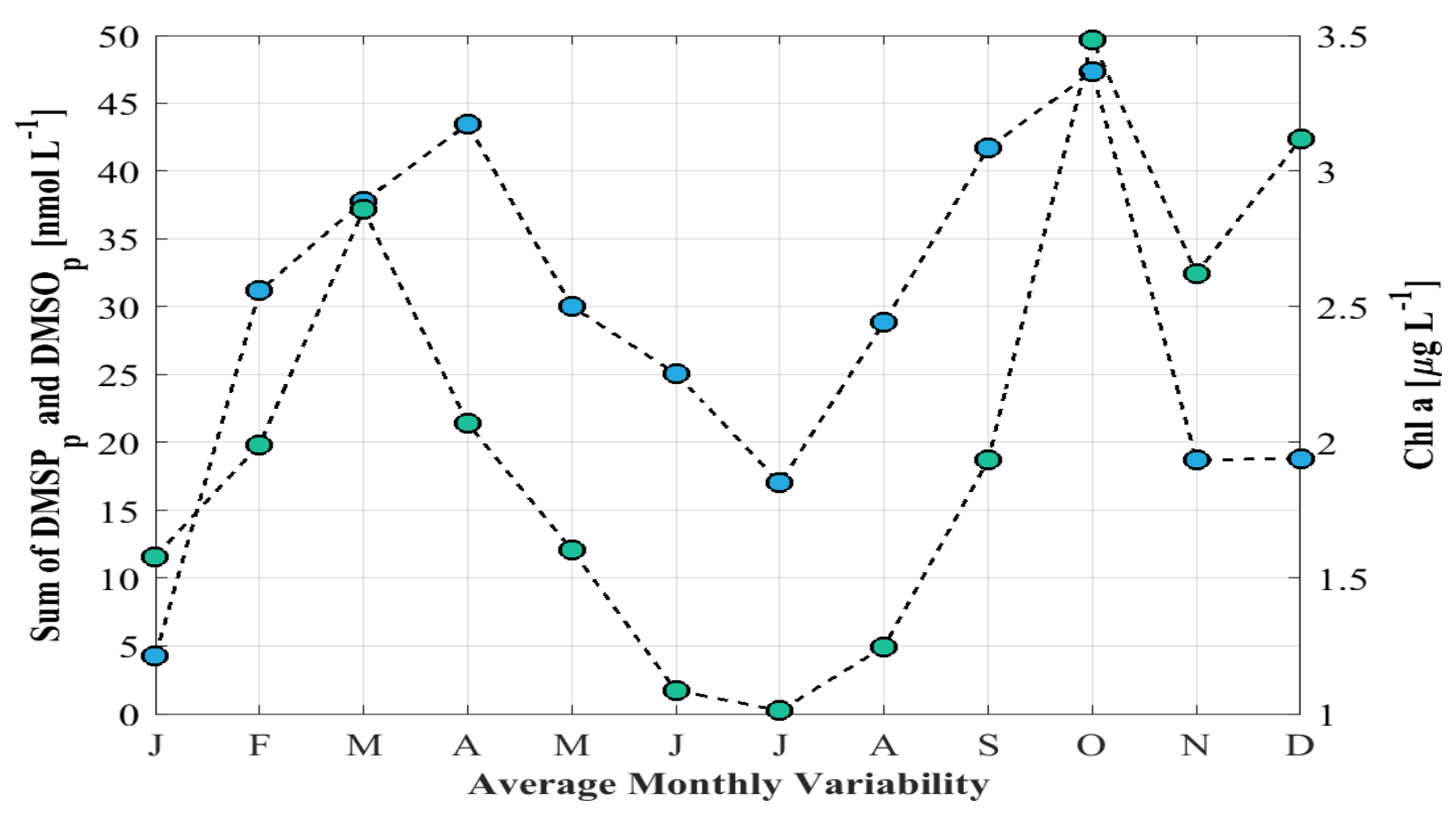

Sum of $\mathrm{DMSP}_{\mathrm{p}}$ and $\mathrm{DMSO}_{\mathrm{p}}$ (blue cycles) and Chl a (green cycles) at mixed layer depth based on mean seasonal calculation.

Generally, mean seasonal cycles of DMSP and DMSO were not dependent on single phytoplankton species at MLD, however, on the whole population. 


\section{Relationship between DMSP $\mathrm{p}_{\mathrm{p}}$ and Dinoflagellates abundance at the bottom layer}

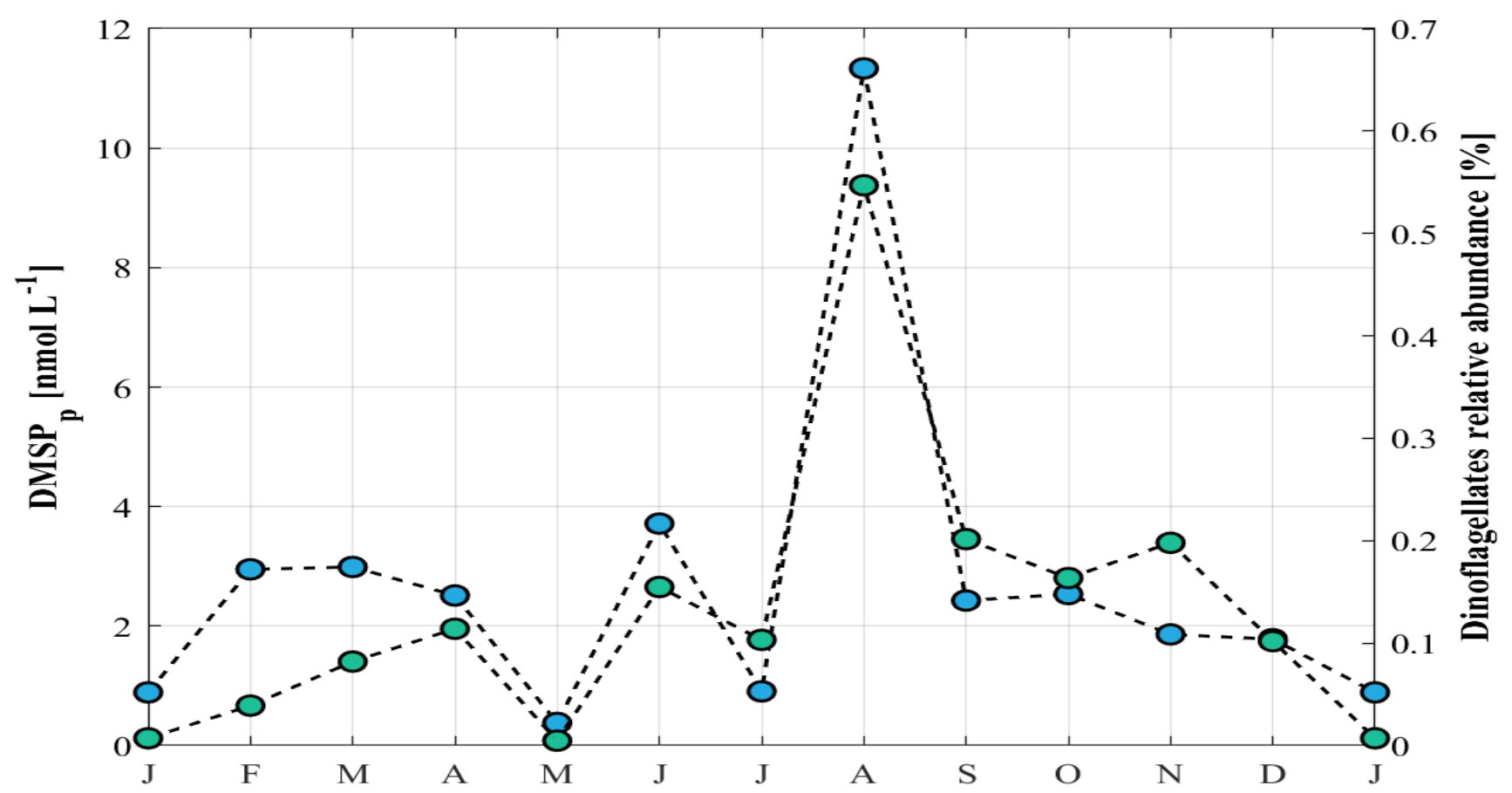

Variations of $\mathrm{DMSP}_{\mathrm{p}}$ (blue cycles) and Dinoflagellates (green cycles) at bottom water $(25 \mathrm{~m})$ based on mean seasonal calculation.

Motility of dinoflagellates helping them to cross the pycnocline to get access to higher nutrient concentrations in deeper water, which can increase the metabolic activity and thus the DMSP production within dinoflagellates compared to stationary phytoplankton in the surface layer. 


\section{Thanks for watching!}

Welcome for any comments(:) 